p-ISSN 2798-0499 e-ISSN 2798-0502

\title{
Factors Affecting the Performance of State Civil Servants at the Education and Culture Services of Kaur District
}

\section{Pengaruh Kualitas Pelayanan dan Kedekatan Emosional terhadap Loyalitas Konsumen di Juragan Mode Kota Bengkulu}

\author{
Yosi Novita Sari1); Ida Ayu Made Ermetha Gyatri2); Nenden Restu Hidayah2) \\ 1)Study Program of Management, Faculty of Economic, Universitas Dehasen Bengkulu \\ ${ }^{2)}$ Department of Management, Faculty of Economic, Universitas Dehasen Bengkulu \\ Email: ${ }^{1}$ novitasariyosi559@gmail.com; ${ }^{2}$ restunenden@gmail.com
}

How to Cite:

Sari, Y. N., Gyatri, I. A. M. E., Hidayah, N. R. (2021). Factors Affecting the Performance of State Civil Servants at the Education and Culture Services of Kaur District. EMAK: Jurnal Ekonomi Manajemen Akuntansi Dan Keuangan, 2(4). DOI: https://doi.org/10.53697/emak.v2i4

\section{ARTICLE HISTORY}

Received [15 Agustus 2021]

Revised [05 October 2021]

Accepted [10 October 2021]

KEYWORDS

Service Quality, Emotional

Closeness and Consumer Loyalty.

This is an open access article under the $C C-B Y$-SA license

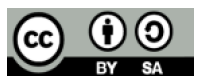

\section{ABSTRAK}

Loyalitas pelanggan adalah proses pengintegrasian yang mengombinasikan pengetahuan untuk mengevaluasi dua prilaku alternative atau lebih, dan memilih salah satu diantara. Banyak faktor yang dapat mempengaruhi loyalitas pelanggan. Produk yang terdiri dari kualitas produk merupakan faktor yang dapat mempengaruhi loyalitas pelanggan. Kualitas layanan dan juga kedekatan emosional. dapat mempengaruhi loyalitas pelanggan. Metode yang digunakan dalam pengambilan data untuk penelitian ini adalah kuesioner. Adapun metode analisis data pada penelitian ini adalah kuantitatif, dan Sampel dalam penelitian ini adalah 140 orang pelanggan. Berdasarkan hasil penelitian ini disimpulkan bahwa : Adapun persamaan regresi yang didapatkan dari hasil penelitian adalah sebagai berikut: $Y=6,263+0,588 X 1+0,574 X 2+$ e. Nilai koefisien diterminasi R2 $=0.792$. Nilai ini mempunyai arti bahwa independen dan dependen, memberikan sumbangan sebesar 79,2 \% dalam mempengaruhi variabel dependen sedangkan sisanya dipengaruhi oleh variabel-variabel lain yang tidak diteliti. Uji t digunakan untuk mengetahui pengaruh masing-masing variabel independen terhadap variabel dependen dengan melihat nilai tsig dibandingkan a 0,05. Dari tabel di atas diperoleh nilai tsig X1 sebesar 0,001, dan X2 sebesar 0,005. Dari nilai tsig yang didapat bahwasanya variabel $X 1$ berpengaruh terhadap $Y$ dan variabel $X 2$ berpengaruh terhadap $Y$, 4). Nilai Fsig 0,002< a 0,05, sehingga dapat disimpulkan bahwa variabel (X1) dan (X2) berpengaruh terhadap variabel (Y) atau secara bersamasama memiliki pengaruh secara simultan.

\section{ABSTRACT}

The method used in collecting data for this research is a questionnaire. The data analysis method in this research is quantitative, and the sample in this study is 140 customers. Based on the results of this study concluded that: The regression equation obtained from the research results are as follows: $Y=6.263+0.588 \times 1+0.574 \times 2+e$. The value of the termination coefficient $R 2=0.792$. This value means that independent and dependent, contributed $79.2 \%$ in influencing the dependent variable while the rest was influenced by other variables not examined. The t test is used to determine the effect of each independent variable on the dependent variable by 
looking at the tsig value compared to 0.05 . From the table above, the tsig value of $X 1$ is 0.001 , and $X 2$ is 0.005 . From the tsig value, it is found that the $X 1$ variable has an effect on $Y$ and the $X 2$ variable has an effect on $Y, 4)$. Fsig value $0.002<0.05$, so it can be concluded that the variables (X1) and (X2) have an effect on the variable (Y) or together have a simultaneous effect.

\section{PENDAHULUAN}

Dewasa ini persaingan antara perusahaan di Indonesia semakin tajam. Persoalan yang dihadapi oleh para pengusaha sekarang ini tidak hanya bagaimana usahanya untuk meningkatkan hasil produksinya, tapi yang lebih penting adalah bagaimana cara menjual barang yang diproduksi tersebut. Persaingan tersebut meliputi persaingan dalam hal penentuan harga, kualitas produk, promosi dan kegiatan distribusi yang cepat dan tepat persaingan ini bertujuan untuk mempertahankan kelangsungan hidup perusahaan, berkembang dan mendapatkan laba. Situasi perekonomian sekarang ini orang dapat bebas memproduksi barang yang mereka sukai, sehingga perusahaan dituntut untuk dapat merebut pasar dalam persaingan yang ketat dengan perusahaan lain, maka setiap perusahaan harus mampu menyusun kegiatan manajemen yang tepat terutama dalam bidang pemasaran.

Loyalitas pelanggan adalah proses pengintegrasian yang mengombinasikan pengetahuan untuk mengevaluasi dua prilaku alternative atau lebih, dan memilih salah satu diantara. Hasil dari proses pengintograsian ini adalah suatu pilihan yang di sajikan secara kognitif sebagai keinginan pelanggan (Etta, 2013: 121). Keputusan membeli adalah tindakan dari pelanggan untuk mau membeli atau tidak terhadap produk. Loyalitas pelanggan adalah suatu keputusan seseorang dimana dia memilih salah satu dari beberapa alternatif pilihan yang ada. Keputusan yang selalu diharapkan oleh produsen, apakah pesan yang disampaikan lewat promosinya telah dapat menjangkau pasar yang telah direncanakan atau belum. Apabila telah menjangkaunya berarti mencerminkan keberhasilan promosinya dan sudah barang tentu dapat menaikkan permintaan pelanggan. Suatu perusahaan memproduksi barang dengan kualitas yang baik, harga relative murah dibandingkan pesaing, dan secara luas tersebar ke berbagai tempat tetapi apabila calon pembeli tidak diberi tahu adanya produk tersebut, diingatkan atau dibujuk untuk membelinya, pelanggan akan bisa membayangkan bahwa produk tersebut tidak akan bias laku dipasaran dan segala sesuatu yang telah dilakukan akan sia-sia.

Perusahaan yang baru berdiri pun harus memasarkan produknya untuk memberitahukan bahwa dipasar ada produk baru, tetapi juga untuk produsen yang produknya mulai memasuki tahap pertumbuhan dalam siklus kehidupan produknya ini dapat menggunakan promosi yang sifatnya membujuk. Pemasaran yang sifatnya mengingatkan dilakukan terutama untuk mempertahankan merk dan image produk di hati pelanggannya, dan ini perlu dilakukan selama tahap kedewasaan didalam siklus kehidupan barang atau jasa sebagai produksinya (Irawan, 2012:45). Dari uraian di atas menggambarkan betapa kompleksnya masalah pemasaran dalam suatu perusahaan, betapa pentingnya system dan strategi yang tepat dalam menyampaikan pesan kepada pelanggannya dengan melalui media pemasaran yang biasanya menggunakan salah satu atau kombinasi dari variabel-variabel pemasaran. Sudah pasti suatu perusahaan ingin selalu meningkatkan jumlah penjualannya untuk mendapatkan laba yang lebih besar, dan kita melihat betapa berperannya pemasaran dalam upaya untuk dapat mencapai tujuan perusahaan yaitu peningkatan volume penjualan.

Banyak faktor yang dapat mempengaruhi loyalitas pelanggan. Produk yang terdiri dari kualitas produk merupakan faktor yang dapat mempengaruhi loyalitas pelanggan. Kualitas layanan dapat mempengaruhi loyalitas pelanggan, karena konsep kualitas sendiri pada dasarnya bersifat relatif, yaitu tergantung pada perspektif atau ciri-ciri yang digunakan untuk menentukan ciri-ciri dan spesifikasi. Jika dianalisis lebih jauh, kualitas akan menguntungkan dalam jangka panjang karena 
keuntungan eksternal yang diperoleh dari kepuasan pelanggan dan keuntungan internal yang diperoleh dari adanya perbaikan efisiensi produk (Senjaya, 2013:45).

Kedekatan emosional mampu memberikan peran peting dalam mempertahankan loyalitas pelanggan. Kedekatan emosional yang dilakukan sangat penting untuk memberikan dorongan, arahan dan penghargaan dari pimpinan ke pada bawahannya sehingga kebutuhan pegawai dalam bentuk pegakuan dan penghargaan terpenuhi dan diharapkan dapat meningkatkan loyalitas pelanggan (Saladin, 2016:23). Kedekatan emosional yang baik akan meingkatkan motivasi seseorang, sebaliknya jika kedekatan buruk maka kinerja yang dihasilkan oleh seseorang akan menjadi kurang maksimal. Juragan Mode merupakan toko yang menjual beragam fashion. Adapun yang menjadi permasalahan adalah Juragan Mode merupakan toko yang bisa bersaing dipasaran, sudah bisa membuat pelanggan untuk melakukan pembelian seperti usaha sejenis. Banyak pelanggan yang sudah merasa puas berbelanja, tetapi masih belum menjadi pelanggan yang loyal di toko Juragan Mode.

\section{LANDASAN TEORI}

\section{Kualitas Pelayanan}

Adalah proses pemenuhan kebutuhan melalui aktivitas orang lain secara langsung pada Juragan Mode di Kota Bengkulu dengan indikator menurut Tjiptono (2015:137) teriri dari reliabilitas, responsivitas, jaminan (assurance), empati serta bukti fisik (tangibles).

\section{Kedekatan Emosional}

Adalah emosional merupakan suatu perasaan dari dalam diri individu dan reaksi pada stimulus dari luar yang mendorong seseorang untuk bertindak lebih dekat pada Juragan Mode di Kota Bengkulu dengan indikator menurut Daryanto (2012:35) terdiri dari menciptakan dan mempertahankan pengaruh yang berkualitas dan perilaku positif dan perilaku suportif

\section{Loyalitas Pelanggan}

Merupakan kelanjutan dari kepuasan pelanggan dalam menggunakan fasilitas maupun jasa pelayanan yang diberikan oleh pihak perusahaan, serta untuk tetap menjadi pelanggan dari pada Juragan Mode di Kota Bengkulu dengan indikator menurut Kotler (2013:145) adalah sebagai berikut: Melakukan pembelian secara berulang dan menunjukkan kekebalan terhadap tarikan dari pesaing, mereferensikan kepada orang lain, membicarakan hal-hal yang positif kepada orang lain dan menunjukkan kekebalan terhadap tarikan dari pesaing.

\section{METODE PENELITIAN}

\section{Regresi Linear Berganda}

Analisis yang digunakan dalam penelitian ini adalah analisis regresi berganda bertujuan untuk memprediksi berapa besar kekuatan pengaruh variabel independen terhadap variabel dependen. Persamaan regresinya adalah (Sugiyono, 2016:54):

$$
Y=a+B 1 X 1+B 2 X 2+B 3 X 3+e
$$

Dimana :

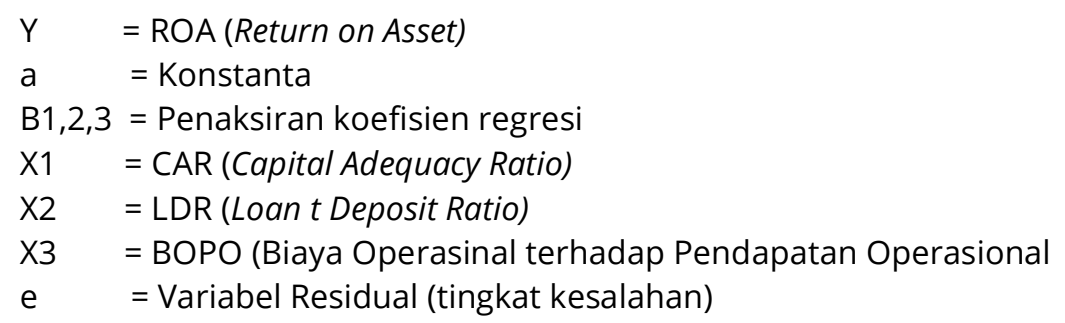


Koefisien Determinasi (R2)

Kekuatan pengaruh variabel bebas terhadap variasi variabel terikat dapat diketahui dari besarnya nilai koefisien determinasi (R2 ) yang berada antara nol dan satu. Nilai yang mendekati satu berarti variabel-variabel independen memberikan hampir semua inforrmasi yang dibutuhkan untuk memprediksi variasi variabel dependen (Ghozali, 2015:82). Interpretasi: Jika R2 mendekati 1 (semakin besar nilai R2 ), menunjukkan bahwa sumbangan atau kontribusi variabel bebas terhadap variabel terikat secara simultan semakin kuat.; dan Jika R2 mendekati 0 (semakin kecil nilai R2 ), menunjukkan bahwa sumbangan atau kontribusi variabel bebas terhadap variabel terikat secara simultan semakin lemah

\section{HASIL DAN PEMBAHASAN}

\section{Analisis Regresi Berganda}

Analisis regresi berganda menggunakan software SPSS, dimana hasil pengujian statistik ini dapat dilihat dalam tabel 1. berikut:

Tabel 1. Hasil Uji Regresi Berganda

\begin{tabular}{|c|c|c|c|c|c|c|c|}
\hline \multirow[b]{2}{*}{ Model } & \multicolumn{2}{|c|}{$\begin{array}{l}\text { Unstandardized } \\
\text { Coefficients }\end{array}$} & \multirow{2}{*}{$\begin{array}{c}\text { Standardized } \\
\text { Coefficients } \\
\text { Beta }\end{array}$} & \multirow[b]{2}{*}{$\mathrm{t}$} & \multirow[b]{2}{*}{ Sig. } & \multicolumn{2}{|c|}{ Collinearity Statistics } \\
\hline & B & Std. Error & & & & Tolerance & VIF \\
\hline $1 \quad$ (Constant) & 6.263 & 3.899 & & .580 & .565 & & \\
\hline $\mathrm{X} 1$ & .588 & .329 & .150 & 8.571 & .001 & .221 & 4.529 \\
\hline$x 2$ & .574 & .292 & .513 & 7.965 & .005 & .222 & 4.507 \\
\hline
\end{tabular}

a. Dependent Variable: $Y$

Sumber: Data yang diolah dari SPSS 16, 2021

Dari perhitungan dengan SPSS versi 16 for windows didapatkan persamaan regresinya adalah :

$\mathrm{Y}=\mathrm{a}+\mathrm{b}_{1} \mathrm{X}_{1}+\mathrm{b}_{2} \mathrm{X}_{2}+\mathrm{e}$

$Y=6,263+0,588 X_{1}+0,574 X_{2}+e$

Angka tersebut masing-masing secara ekonomi dapat dijelaskan sebagai berikut:

1. Nilai konstanta $=6,263$ Bernilai positif maka artinya jika nilai variabel kualitas pelayanan $\left(\mathrm{X}_{1}\right)$ dan kedekatan emosional $\left(\mathrm{X}_{2}\right)$ dianggap tidak ada atau sama dengan 0 , maka nilai loyalitas konsumen akan semakin bertambah atau mengalami peningkatan yaitu 6,263

2. Nilai koefisien variabel $\left(\mathrm{X}_{1}\right)$. Bernilai positif yaitu 0,588 artinya apabila kualitas pelayanan mengalami kenaikan satu satuan, maka nilai loyalitas konsumen akan mengalami peningkatakan sebesar 0,588 dengan asumsi variabel kedekatan emosional $\left(\mathrm{X}_{2}\right)$ nilainya konstan.

3. Nilai koefisien variabel kedekatan emosional $\left(X_{2}\right) 0,574$. Bernilai positif yaitu 0,574 artinya apabila kualitas pelayanan mengalami kenaikan satu satuan, maka nilai loyalitas konsumen akan mengalami peningkatan sebesar 0,574 satuan dengan asumsi variabel $X_{1}$ nilainya konstan 
Uji Koefisien Determinasi (R Square)

Tabel 2. Hasil Ujikoefisien Determinasi (R Square)

Model Summary ${ }^{b}$

\begin{tabular}{|l|c|r|r|r|r|}
\hline \multicolumn{1}{|c|}{ Model } & $\mathrm{R}$ & $\mathrm{R}$ Square & Adjusted R Square & Std. Error of the Estimate & Durbin-Watson \\
\hline 1 & $.890^{\mathrm{a}}$ & .792 & .790 & 3.962 & 2.239 \\
\hline
\end{tabular}

a. Predictors: (Constant), X2, X1

b. Dependent Variable: $Y$

Sumber : Data yang diolah dari SPSS 16, 2021

Bedasarkan uji hasil koefesien determinasi, maka dapat diperoleh persamaan sebagai berikut :

Nilai R Square adalah sebesar 0,792

$\mathrm{Kd}=0.792 .100 \%$

$\mathrm{Kd}=79,2 \%$

Dari tabel di atas menujukan bahwa nilai koefisien diterminasi $R^{2}=0.792$. Nilai ini mempunyai arti bahwa variabel independen berpengaruh terhadap variabel dependen sebesar 79,2 \% sedangkan sisanya dipengaruhi oleh variabel-variabel lain yang tidak diteliti.

Uji Hipotesis

Uji Parsial ( Uji t )

Tabel 3. Hasil Uji Parsial ( Uji T )

Coefficients $^{a}$

\begin{tabular}{|c|c|c|c|c|c|c|c|c|}
\hline \multirow[b]{2}{*}{ Model } & & \multicolumn{2}{|c|}{$\begin{array}{l}\text { Unstandardized } \\
\text { Coefficients }\end{array}$} & \multirow{2}{*}{$\begin{array}{c}\text { Standardized } \\
\text { Coefficients } \\
\text { Beta }\end{array}$} & \multirow[b]{2}{*}{ l } & \multirow[b]{2}{*}{ Sig. } & \multicolumn{2}{|c|}{$\begin{array}{l}\text { Collinearity } \\
\text { Statistics }\end{array}$} \\
\hline & & B & Std. Error & & & & Tolerance & VIF \\
\hline & (Constant) & 6.263 & 3.899 & & .580 & .565 & & \\
\hline & $\mathrm{X} 1$ & .588 & .329 & .150 & 8.571 & .001 & .221 & 4.529 \\
\hline & $X 2$ & .574 & .292 & .513 & 7.965 & .005 & .222 & 4.507 \\
\hline
\end{tabular}

a. Dependent Variable: $Y$

Sumber: Data yang diolah dari SPSS 16, 2021

Uji t digunakan untuk mengetahui pengaruh masing-masing variabel independen terhadap variabel dependen dengan melihat nilai $t_{\text {sig }}$ dibandingkan a 0,05 . Dari tabel di atas diperoleh nilai $t_{\text {sig }} X_{1}$ sebesar 0,001 , dan $X_{2}$ sebesar 0,005 . Dari nilai $t_{\text {sig }}$ yang didapat bahwasanya variabel $X_{1}$ berpengaruh terhadap $\mathrm{Y}$ dan variabel $\mathrm{X}_{2}$ berpengaruh terhadap $\mathrm{Y}$.

Uji Simultan ( Uji F )

Uji simultan ( uji f ) dilakukan menggunakan SPSS 16 dengan nilai $a=0,05$ berikut adalah hasil uji simultan (uji f). 
Tabel 4. Hasil Uji Simultan ( Uji F )

\begin{tabular}{|ll|r|r|r|r|r|}
\hline \multicolumn{7}{|c|}{ ANOVA $^{\mathrm{b}}$} \\
\hline 1 & & Sum of Squares & \multicolumn{1}{c|}{ Df } & Mean Square & F & \multicolumn{1}{c|}{ Sig. } \\
\hline & Regression & 1246.435 & 3 & 415.478 & 26.463 & $.002^{\mathrm{a}}$ \\
& Residual & 1507.205 & 96 & 15.700 & & \\
& Total & 2753.640 & 99 & & & \\
\hline
\end{tabular}

a. Predictors: (Constant), X3, X2, X1

b. Dependent Variable: $Y$

Sumber : Data yang diolah dari SPSS 16, 2021

Berikut ini adalah hasil uji $\mathrm{f}$, hasil uji $\mathrm{f}$ digunakan untuk mengetahui apakah model dalam penelitian telah layak untuk digunakan. Berdasarkan tabel di atas diperoleh nilai $F_{\text {sig }} 0,002<a$ 0,05 , sehingga dapat disimpulkan bahwa variabel $(\mathrm{X} 1)$ dan $(\mathrm{X} 2)$ berpengaruh terhadap variabel $(\mathrm{Y})$ atau secara bersama-sama memiliki pengaruh secara simultan.

\section{Pembahasan}

1. Pengaruh Kualitas Pelayanan Terhadap Loyalitas Konsumen Toko Juragan Mode Kota Bengkulu

Berdasarkan penelitian yang telah dilakukan oleh peneliti bahwa nilai $\mathrm{t}_{\mathrm{sig}} \mathrm{X}_{2}$ sebesar 0,005 . Dari nilai $t_{\text {sig }}$ yang didapat bahwasanya variabel $X_{2}$ berpengaruh terhadap variabel $Y$. Hasil ini mendukung penelitian yang memperlihatkan bahwa kualitas pelayanan berpengaruh terhadap kepuasan pelanggan (Danaher \& Colgate, 2000). Dalam hal ini kualitas dianggap sebagai ukuran relatif kebaikan suatu produk atau jasa (Tjiptono, 2006). Sehingga dalam rangka menaikkan nilai pelanggan perusahaan harus melakukan peningkatan citra perusahaan di mata pelanggan yang selalu harus dipertahankan dan secara berkala ditingkatkan dengan melakukan peningkatan kualitas pelayanan yang baik dan prima. Secara searah pula maka akan terjadi kedekatan emosional yang kuat antara Bank UMKM Jawa Timur Cabang Ngawi dengan pelanggannya. Sebagaimana telah diungkapkan bahwa dengan meningkatnya kekuatan emosional secara positif terhadap penyedia jasa, maka akan semakin meningkat pula loyalitasnya (Sierra \& McQuity, 2005). Dengan meningkatnya masing-masing faktor tersebut maka akan dapat dipastikan bahwa loyalitas pelanggan juga akan meningkat pula.

2. Pengaruh Kedekatan Emosional Terhadap Loyalitas Konsumen Toko Juragan Mode Kota Bengkulu

Berdasarkan penelitian yang telah dilakukan oleh peneliti bahwa nilai $t_{\text {sig }} X_{1}$ sebesar 0,001 . Dari nilai $t_{\text {sig }}$ yang didapat bahwasanya variabel $X_{1}$ berpengaruh terhadap $Y$.. Signifikansi komunikasi pemasaran terpadu sebesar 0,000 lebih kecil dari nilai anova 0,05 yang menunjukkan variabel kedekatan emosional terpadu berpengaruh positif signifikan terhadap loyalitas konsumen. Ini berarti semakin tinggi perusahaan menerapkan kedekatan emosional pada produknya maka semakin tinggi pula loyalitas konsumen terhadap produk tersebut.

Penelitian yang telah dilakukan oleh peneliti ini, didukung oleh penelitian terdahulu yang dilakukan oleh Dinda (2010), hasil pengujian diperoleh nilai t untuk variabel kedekatan emosional menunjukkan nilai $t=3,909$ dengan nilai signifikansi sebesar $0,000<0,05$. Dengan nilai signifikansi di bawah 0,05 tersebut menunjukkan bahwa kedekatan emosional memiliki pengaruh yang signifikan terhadap loyalitas pelanggan. Hal ini berarti Hipotesis diterima. Arah koefisien regresi positif berarti bahwa kedekatan emosional memiliki pengaruh positif yang signifikan terhadap loyalitas pelanggan. Semakin tinggi kedekatan emosinal yang dirasakan pelanggan dengan pihak manajemen bank akan semakin tinggi pula loyalitas pelanggan, sebaliknya semakin rendah kedekatan emosional yang dirasakan pelanggan semakin rendah 
p-ISSN 2798-0499 e-ISSN 2798-0502

pula tingkat loyalitasnya.

Berdasarkan hasil penelitian Iwan Noor Suhasto (2018) menunjukkan bahwa Secara umum penelitian ini menunjukkan hasil yang memuaskan. Hasil analisis pengujian secara simultan dari kedua variabel bebas, yaitu kualitas pelayanan dan kedekatan emosional berpengaruh secara signifikan terhadap loyalitas konsumen. Selanjutnya diperoleh bahwa variabel pembentuk loyalitas memiliki pengaruh yang positif dan signifikan terhadap loyalitas pelanggan. Hal ini dikarenakan bahwa dengan kualitas pelayanan serta kedekatan emosional yang dimiliki oleh perusahaan terbukti dapat menciptakan loyalitas dalam diri konsumen.

3. Pengaruh Kualitas Pelayanan dan Kedekatan Emosional Terhadap Loyalitas Konsumen Toko Juragan Mode Kota Bengkulu

Berdasarkan penelitian yang telah dilakukan oleh peneliti bahwa hasil uji $f$ (simuultan) digunakan untuk mengetahui apakah Kualitas Pelayanan $\left(X^{1}\right)$ dan Kedekatan Emosional $\left(X^{2}\right)$ Berpengaruh Terhadap Loyalitas Konsumen ( $Y$ ). Hasil yang diperoleh adalah nilai $F_{\text {sig }} 0,002<a$ 0,05 , sehingga dapat disimpulkan bahwa variabel (X1) dan (X2) berpengaruh terhadap variabel (Y) atau secara bersama-sama memiliki pengaruh secara simultan. Penelitian yang telah dilakukan oleh peneliti ini, didukung oleh penelitian terdahulu yang dilakukan oleh Tiya Gita Pawitra, STIE PERBANAS Surabaya (2013). Pengaruh Kualitas Layanan Dan Kedekatan emosional Terhadap Kualitas Hubungan Dan Loyalitas Pelanggan KFC Di Surabaya. Hasil penelitian menunjukan bahwa kualitas layanan berpengaruh signifikan positif terhadap kedekatan emosional, kedekatan emosional berpengaruh signifikan positif terhadap loyalitas pelanggan dan kedekatan emosional berpengaruh signifikan positif terhadap kualitas hubungan. Secara keseluruhan responden menanggapi bahwa kualitas hubungan yang terjadi dengan KFC dinilai baik dan termasuk dalam kategori setuju dengan rata-rata sebesar 3,83.

\section{KESIMPULAN DAN SARAN}

\section{Kesimpulan}

1. Adapun persamaan regresi yang didapatkan dari hasil penelitian adalah sebagai berikut: $Y=$ $6,263+0,588 \times 1+0,574 \times 2+e$

2. Nilai koefisien diterminasi $\mathrm{R} 2=0.792$. Nilai ini mempunyai arti bahwa independen dan dependen, memberikan sumbangan sebesar 79,2 \% dalam mempengaruhi variabel dependen sedangkan sisanya dipengaruhi oleh variabel-variabel lain yang tidak diteliti.

3. Uji t digunakan untuk mengetahui pengaruh masing-masing variabel independen terhadap variabel dependen dengan melihat nilai tsig dibandingkan a 0,05. Dari tabel di atas diperoleh nilai tsig X1 sebesar 0,001, dan X2 sebesar 0,005. Dari nilai tsig yang didapat bahwasanya variabel $\mathrm{X} 1$ berpengaruh terhadap $\mathrm{Y}$ dan variabel $\mathrm{X} 2$ berpengaruh terhadap $\mathrm{Y}$

4. Nilai Fsig $0,002<a 0,05$, sehingga dapat disimpulkan bahwa variabel (X1) dan (X2) berpengaruh terhadap variabel $(\mathrm{Y})$ atau secara bersama-sama memiliki pengaruh secara simultan

Saran

1. Agar hasil penelitian dapat dijadikan sebagai bahan pertimbangan bagi pemilik usaha, agar dapat meningkatkan kualitas pelayanan dan kedekatan emosional dan dapat menjadikan usaha lebih baik lagi untuk kemajuan kedepannya.

2. Bagi Penulis agar penelitian ini dapat menambah ilmu dan pengetahuan yang telah dipelajari dan agar penulis mampu mengembangkan kemampuan dalam menganalisa permasalahan dalam dunia bisnis/ekonomi yang sebenarnya.

3. Bagi Peneliti lainnya sebagai referensi yang dapat dijadikan sebagai bahan perbandingan dalam melakukan penelitian dimasa yang akan datang, khususnya. 


\section{DAFTAR PUSTAKA}

Arikunto, Suharsimi. 2016. Prosedur Penelitian Suatu Pendekatan Praktik. Jakarta: Rineka Cipta

Daryanto. 2012. Sari Kuliah Menajemen Pemasaran. Bandung: PT Sarana Tutorial Nurani Sejahtera

Dirgantoro, F. 2014. Manage Your Career. Jakarta: Elex Media Komputindo

Etta, Mamang Sangadji \& Sopiah. 2013. Perilaku Konsumen-Pendekatan Praktis disertai Himpunan Jurnal Penelitian. Yogyakarta: ANDI

Hasan, Ali. 2014. Marketing dan kasus-kasus pilihan cetakan 1. Yogyakarta: CAPS

Hidayah, N. R. (2020). Effect Of Education And Training (diklat/bimtek), Understanding Of Regional Financial Accounting Systems (Simda) On Performance Of Regional Financial Management. BIMA Journal (Business, Management, \& Accounting Journal), 1(1), 61-72.

Irawan. 2012. Manajemen Pemasaran Modern Edisi ke-2. Yogyakarta: Liberty Offset.

Kertajaya. 2014. Herman. Strategi Marketing Plus. Gramedia: Jakarta.

Kotler 2013. Manajemen Pemasaran. Edisi 13. Jakarta: Erlangga

Kotler, Amstrong. 2015. Prinsip-Prinsip Pemasaran, Edisi keduabelas, Jilid 1. Jakarta: Erlangga

Levit. 2015. Imajinasi Pemasaran. Jakarta: Erlangga

Lukman. 2012. Prinsip-prinsip Pemasaran Jilid 1. Jakarta: Erlangga

Malayu S.P 2016, Manajemen Sumber Daya Manusia Perusahaan. Bandung, PT. Bumi Aksa

Mardiana, Lusi. 2018. Hubungan Custemer Eksperience dan Persepsi Konsumen Dengan Keputusaan Pembelian Pada Minimarket Koya Kota Bengkulu.

Moenir. 2012. Manajemen Pelayanan Umum di Indonesia. Jakarta:Bumi Aksara

Pawitra, Tiya Gita. 2013. Pengaruh Kualitas Layanan Dan Kepuasan Emosional Terhadap Kualitas Hubungan Dan Loyalitas Pelanggan KFC Di Surabaya

Rangkuti, Freddy. 2011. Strategi Promosi yang Kreatif dan Analisis Kasus. Integrated Marketing. Jakarta : Gramedia Pustaka Utama.

Robhins. 2015. Kebutuhan Dasar Manusia I. Jakarta : Kemenkes RI

Saladin. 2016. Perilaku Konsumen: Teori dan Penerapannya dalam Pemasaran, Cetakan Pertama. Jakarta: Ghalia Indonesia

Sastradipoera. 2012. Manajemen Marketing Suatu Pendekatan Ramuan Marketing. Bandung: KappSigma

Schiffman dan Kanuk. 2017. Pemasaran. Jilid Kedua. Jakarta: Salemba Empat.

Senjaya et al, 2013. Manajemen Pemasaran dan Pemasaran Jasa. Bandung: CV Alfabeta

Sugiyono. 2016. Metode Penelitian Manajemen. Bandung : Alfabeta

Supranto. 2016. Pengukuran Tingkat Kepuasan Pelanggan : Untuk Menaikkan Pangsa Pasar, Jakarta, Rineka Cipta

Thompson. 2016. Crafting \& Executing Strategy; The Quest for. Competitive advantage, sixteenth edition, McGraw-Hill International

Tjiptono. 2015. Manajemen Strategic. Yogyakarta: ANDI Yogyakarta

Trisnaningsih, Yuli. 2013. Pengaruh Kedekatan Emosional Pegawai Terhadap Kualitas Pelayanan Peserta Pendidikan Dan Pelatihan Pada Badan Kepegawaian Pendidikan Dan Pelatihan Daerah Provinsi Sulawesi Tengah.

Wirawan. 2012. Kepemimpinan, Teori, Psikologi, Perilaku Organisasi, Aplikasi dan Penelitian:Contoh Aplikasi untuk Kepemimpinan Wanita, Organisasi Bisnis, Pendidikan dan Militer. Jakarta: Rajagrafindo Persada. 